\title{
Book review: The Emergence of Pressure Blade Making
}

\author{
Christian Steven Hoggard
}

\author{
Centre for the Archaeology of Human Origins, University of Southampton, United Kingdom. \\ Email: C.Hoggard@soton.ac.uk and ch20g09@soton.ac.uk
}

The Emergence of Pressure Blade Making - From Origin to Modern Experimentation

Edited by Pierre M. Desrosiers

Springer Publishing, 2012, pp. 536. ISBN 978-1-4614-2003-3

http://www.springer.com/social+sciences/anthropology+\%26+archaeology/book/978-1-4614-2002-6

This ambitious volume represents the outcome of a session held in honour of two key figures in the study of pressure blade manufacture, Jacques Tixier and Marie-Louise Inizan, on pressure blade production at the 2006 congress of the International Union of Prehistoric and Protohistoric Sciences (IUPPS) held in Lisbon, Portugal. This nineteen chapter publication is a synthesis of this session focussing on the invention, diffusion and the adoption (or reinvention) of pressure blade making throughout the Old and New Worlds. This volume can be divided into three main parts.

Published by the School of History, Classics and Archaeology, University of Edinburgh ISSN: 2055-0472. URL: http://journals.ed.ac.uk/lithicstudies/

This work is licensed under a Creative Commons Attribution 2.5 UK: Scotland License. 
An introductory chapter by Pierre Desrosiers is followed by two chapters that focus on the historical framework of pressure blade manufacture. Marie-Louise Inizan starts her chapter by highlighting the quintessential research by Jacques Tixier into pressure débitage, with respect to his work in the Epipalaeolithic of the Maghreb, and the importance of the 1964 Lithic Technology Symposium of Les Eyzies. Following this Inizan stresses the role pressure débitage has played in the identification of many prehistoric cultures (e.g., the Japanese "microblade tradition"). This is then followed by an overview of Mesoamerican blade experiments from the earliest translations by Edward Tylor to much more recent work of Greg Nunn and James Winn. These chapters are excellent in communicating the history and the breadth of the subject, even including the lesser known experiments by Marc Hintzman and Andrei Tabarev, whilst providing non-specialists with a general introduction into the methods and techniques of pressure blade percussion.

The main body of the text, consisting of fourteen chapters, focusses on current issues and debates within the archaeological evidence for pressure blade production around the world, or more specifically where it has been identified (Asia, Europe, Africa and the Americas). Emphasis is placed on the origins of pressure flaking in Upper Palaeolithic contexts (Chapters 11, 12 and 15) until the terminal period of the Pleistocene (Chapters 4, 9 and 17). As Desrosiers stresses, most of the chapters were written by contributors who are not native English speakers, and as a result, present a unique opportunity for readers to access data and interpretations that are not typically available in the English language. These chapters are refreshing in the variety of methodological frameworks adopted to understand concepts such as local innovation and diffusion, and technological behaviour. The use of frameworks incorporating palaeoenvironmental (Chapter 4) culture-historic (Chapter 12), spatial (Chapter 10), and chronometric (Chapter 11) datasets and analyses, in addition to archaeological and experimental lithic analysis, provide a holistic approach that should be applauded.

The final two chapters focus on recent advances in the experimentation of pressure blade making. Jacques Pelegrin highlights, effectively, how experimental replication reference collections still remain essential to the identification of various elements of archaeological production including the varying scales of added pressure, platform preparation, the different sequences in blade production, and the transmission and development of these techniques. Pelegrin also successfully highlights how various "modes", or methods of technological production are near impossible without a posteriori knowledge. This book closes with ongoing research and a progress report into "measurable flintknapping", i.e. the absolute repeatability and precision of flintknapping experiments through engineered detachment machines and lever systems, by Kelterborn. Kelterborn tackles through issues within measurable flintknapping such as torsion, fine tuning experiments, and fracture propagation. A great balance is achieved by credibly analysing variables through robust experimentation, whilst acknowledging that detachment machines do not (and should not) substitute knowledge and experience in traditional flintknapping. Typically inaccessible to readers, due to issues of terminology and research depth, Kelterborn finishes the edited volume by writing about experimentation in lever systems in a manner that is clear and accessible.

This volume would benefit from a more thorough discussion of why pressure blades were adopted. It is felt that whilst certain chapters attempt to tackle this issue, they feature a framework that is largely based on the economics of blade production, with less attention on more social and behavioural aspects of technological evolution and innovation. Overall, this volume should be commended for its successful and holistic effort in highlighting phenomena associated with pressure blade production through experimental, archaeological and historical investigations. This almost Herculean effort is clear, concise and marks a milestone in studies of blade technology. It is quintessential for anyone interested in studies of pressure blade production. 